\title{
Potential late effects of SARS-CoV-2 (COVID-19) infection: parallels to cancer late effects
}

\author{
Richard P. Phipps ${ }^{1} \cdot$ Patricia J. Sime ${ }^{2} \cdot$ Connor R. Phipps ${ }^{3}$ \\ Accepted: 30 December 2020 / Published online: 4 February 2021 \\ (C) The Author(s), under exclusive licence to Springer Science+Business Media, LLC part of Springer Nature 2021
}

"Corona virus: a simple pathogen causing complex disease. Will there be dangerous late effects in the years ahead?"

The purpose of this Editorial is to postulate that SARSCoV-2 (COVID-19) virus infection can cause subsequent "late effects." Late effects are tissue-damaging events that by definition occur months or years after an initial insult. These late effects, well recognized in oncology, may also be caused by virus infection and the ensuing host reaction, even long after the viral infection itself has resolved.

The so-called late effects cause deleterious consequences months or years after disease treatment. These consequences have been most prominent in the treatment of many types of cancers. Cancer itself, and many cancer treatments such as ionizing radiation and cancer chemotherapy, can all contribute to late effects. Examples include skin scarring, lung and other organ fibrosis, bone marrow damage, peripheral neuropathy, and more [1]. These cancer-related late effects vary in their severity and are now well known with significant morbidity and even rarely mortality.

What about viruses and late effects? Without going into the pathophysiology in detail, one example includes the varicella (chickenpox) virus. Following primary infection with varicella, the virus can reactivate months or years later causing

\section{Richard P. Phipps}

Richmond, USA

2 Department of Medicine, Virginia Commonwealth University, Richmond, VA, USA

3 Dept. of Biomedical Engineering, University of Wisconsin-Madison, Madison, WI, USA painful "shingles." This can be prevented by the new antishingles vaccines. Nonetheless, there are many people who develop viral reactivation decades after their initial infection.

What about the SARS-CoV-2 virus? As we now know, viral infection ranges from virtually asymptomatic to deadly. Death can occur even with highly supportive care in an ICU setting. The "cytokine storm" that happens in some patients appears to primarily affect the lung. However, other organ systems such as the heart, gut, and reproductive organs can be involved in the infection or systemic inflammatory response.

What about host immune responses? Now, on top of the damage caused by SARS-CoV-2, additional injury from host immune and anti-viral responses may occur. These responses include the production of potent lipid mediators such as prostaglandins and proteins such as cytokines and antibodies. These are thought to be part of both inflammatory and resolution [2] processes. In cases where patients have severe disease, we postulate that late effects such as lung injury could occur with remodeling and possibly fibrosis. Even now, a subset of patients who recover are showing signs of "late effects" that include prolonged lung filtrates, lung function impairment, and even cardiomyopathy (see Fig. 1). We await further data to better understand the duration and or severity of these changes. Will some of these abnormalities resolve or will there be patients who have permanent end-organ damage? It seems prudent that health care providers be aware of these possibilities and monitor for them. Deciphering the roles of viruses, host responses, and our therapies will be important. 


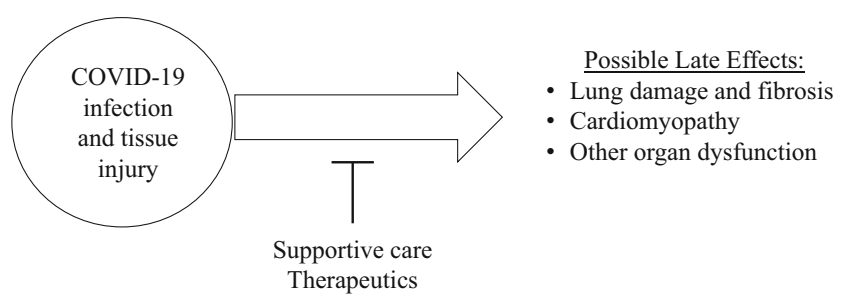

Fig. 1 Following infection with COVID-19, tissue injury is incited by the virus and host immune and inflammatory responses causing organ dysfunction. We postulate in certain cases this may lead to late effects, similar to those seen in oncology. How this is modified by therapies will become evident as data is collected

There is great excitement over the availability of highly efficacious vaccines [3]. We hope that vaccines will prevent or mitigate infection for most people and hopefully mitigate or prevent late effects. Similarly, many patients have already received several types of therapy as part of clinical care or in clinical trials (including supplemental oxygen, patient positioning (prone positioning), mechanical ventilation, steroids, anticoagulation, antivirals, monoclonal antibodies, anticytokine therapies, and others). How these therapies impact late effects will become more apparent as we gather additional data and as time goes by.

\section{References}

1. Klonoff-Cohen, H., \& Polavarapu, M. (2020). Existence of lateeffects instruments for cancer survivors: A systematic review. PloS one, 15(2), e0229222. https://doi.org/10.1371/journal.pone. 0229222.

2. Panigrahy, D., Gilligan, M. M., Huang, S., Gartung, A., Cortés-Puch, I., Sime, P. J., Phipps, R. P., Serhan, C. N., \& Hammock, B. D. (2020). Inflammation resolution: A dual-pronged approach to averting cytokine storms in COVID-19? Cancer Metastasis Rev, 39(2), 337-340. https://doi.org/10.1007/s10555-020-09889-4.

3. Ghaebi, M., Osali, A., Valizadeh, H., Roshangar, L., \& Ahmadi, M. (2020). Vaccine development and therapeutic design for 2019nCoV/SARS-CoV-2: Challenges and chances. J Cell Physiol, 235(12), 9098-9109. https://doi.org/10.1002/jcp.29771.

Publisher's note Springer Nature remains neutral with regard to jurisdictional claims in published maps and institutional affiliations. 